\title{
Study on the Mechanism and Effect of a Partition Wall Controlling Foundation Pit Deformation in the Soft-Soil Area
}

\author{
Chunlei Feng $\left(\mathbb{D},{ }^{1}\right.$ Dingli Zhang, ${ }^{2}$ Hualao Wang, ${ }^{1}$ and Xuan Zhang ${ }^{1}$ \\ ${ }^{1}$ Bridge and Tunnel Research Center, Research Institute of Highway, Ministry of Transport, Beijing 100088, China \\ ${ }^{2}$ Key Laboratory for Urban Underground Engineering of Ministry of Education, Beijing Jiaotong University, \\ Beijing 100044, China \\ Correspondence should be addressed to Chunlei Feng; fclbjtu@163.com
}

Received 20 January 2022; Revised 7 February 2022; Accepted 10 February 2022; Published 7 March 2022

Academic Editor: Jianyong Han

Copyright (c) 2022 Chunlei Feng et al. This is an open access article distributed under the Creative Commons Attribution License, which permits unrestricted use, distribution, and reproduction in any medium, provided the original work is properly cited.

\begin{abstract}
Based on the soft-soil layer and several practical subway stations projects, the effect of partition wall main parameters on internal force and the deformation of retaining structure was thoroughly investigated via numerical simulation and orthogonal experiment. Results show that the influence of distance between partition wall and retaining structure, $L$, on controlling the internal forces of the retaining structure and maximum ground settlement, is more obvious; the maximum settlement can be reduced by more than $60 \%$. Moreover, the influence of partition wall depth under the ground, $H$, within a certain range can substantially reduce the maximum lateral palisade structure; the lateral displacement can be reduced by about 50\%; however, within the scope of the economic, the stiffness of the partition wall, $E$, with impact on retaining structure internal force and deformation is relatively weak. Finally, the applicability of the research results is verified.
\end{abstract}

\section{Introduction}

The deformation control measures of foundation pit engineering can be divided into three categories [1]: ensuring the stability of the foundation pit itself during the construction process, improving the ability of the surrounding environment to resist deformation, and cutting off or reducing the influence of soil deformation on the surrounding environment through the partition method. In a soft-soil area, a partition wall in the form of cast-in-place pile, mixing pile, and so on has been used in many projects as the main measure to control the influence of foundation pit deformation on the surrounding.

At the moment, studies on the engineering application of partition walls in the domestic and overseas are primarily focused on two aspects: (1) the pilot-isolation pile-wall system used to control the impact of tunnel excavation on the surrounding environment is studied, and the key influencing factors [2] and theoretical model [3] of the system are summarized by combining analytical solutions and numerical simulation methods. (2) pile-wall partition wall (hereinafter referred to as partition wall) is used to control the influence of foundation pit or tunnel excavation on adjacent buildings (structures). The most commonly used methods are numerical simulation [4-10] and orthogonal test [11], or partition wall design parameters are discussed using the evaluation index of partition wall control effect $[12,13]$. Moreover, the majority of existing studies concentrate on the qualitative analysis of the impact of changing the main design parameters of partition walls on the deformation control effect of surrounding buildings (structures). The favorable change range and reasons of each parameter on the control effect cannot be accurately determined. Hence, the partition wall still needs to rely on engineering experience for design and construction. Furthermore, the research background is primarily for a specific project, and the research conclusion's general applicability is limited. As a result, the mechanism of partition wall control over foundation pit deformation needs to be investigated further.

In this study, based on the foundation pit engineering of the Tianjin Metro Line 5 and Line 6 in China, and based on 
the analysis of the measured displacement data of the retaining structure and surface settlement and existing literature [14] on the study of the deformation law of foundation pit excavation of metro station in this soft-soiled area, the finite element analysis and orthogonal test combining the small strain characteristics of soil are used. The calculation theory of "similar structure" double-row piles is used to establish a quantitative relationship between the partition wall design parameters and deformation control effect. Finally, the prediction theory of the foundation pit deformation by Kung et al., based on the reliability method, is used to validate its mechanism of action, thereby making control measures more reasonable and effective.

\section{Applicable Conditions and Mechanism of the Partition Wall: A Brief}

For a building with high-protection grade in the adjacent foundation pit, the distance between the foundation pit retaining structure and the protected object should be more than $1.2 \sim 1.5$ times the excavation depth of the foundation pit. If the minimum safe distance cannot be met and the stiffness of the envelope is already high, the tracking compensation method, foundation underpinning method, and partition method [15] are commonly used as protection measures. The tracking compensation method is one of them. It belongs to the "dynamic deformation control" category, and its main principle is to timely supplement ground loss through grouting during the foundation pit construction process to ensure that the construction technology and grouting time grasp requirements are high. The main principle of the foundation underpinning method is to improve the bearing capacity of the foundation by strengthening the soil beneath the foundation of the building before excavation to control the settlement of the building. However, this method causes significant soil disturbance, and improper operation will aggravate the uneven settlement of the building.

As shown in Figure 1, the partition wall is usually placed between surrounding buildings (structures) and the foundation pit as the primary control measure to cut off the propagation path of foundation pit deformation. The range of plane setting is generally at least equal to the range of buildings requiring settlement control, and the range of vertical setting must generally pass through the possible slip surface. It primarily constructs palisade structures and excavates lateral Earth pressure and friction resistance caused by differential settlement. To some extent, it can share the Earth pressure on retaining structures and limit the deformation of development restrictions, while also improving the ability of shear slip surface and reducing the foundation settlement caused by building precipitation and the effect of content. In comparison to the previous two control measures, the construction speed is fast and the operation is simple.

\section{Project Background}

3.1. Project Summary. The Tianjin Metro Line 5 starts from Shuangjie, Beichen District, in the north and ends at Liyuantou, Xiqing District, in the south. The total length of

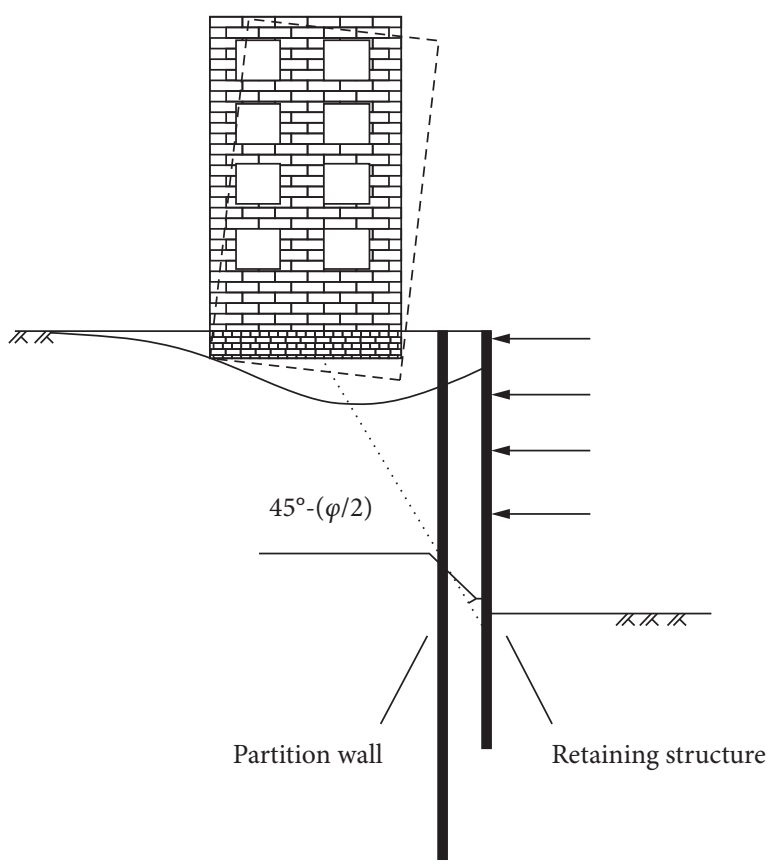

FIGURE 1: Schematic for the layout of the partition wall.

the line is $34.8 \mathrm{~km}$, including a $33 \mathrm{~km}$ underground line and a $1.8 \mathrm{~km}$ ground line and transition section. Line 6 starts from Dabizhuang in the north and ends at Meilin Road in the south. The total length of the line is $41.6 \mathrm{~km}$, including the $39.8 \mathrm{~km}$ underground line, $0.8 \mathrm{~km}$ ground line and transition section, and $1.0 \mathrm{~km}$ elevated line. The two lines run through the East, West, North, and South of Tianjin, covering a wide area, and the regional stratum represents the characteristics of the typical soft-soil layer in Tianjin.

3.2. Metro Station Foundation Pit Standardization. In this study, a total of 20 excavation pits of the Tianjin Metro station, which are combined forms of inner support and ground wall, are collected with an open-cut method of Line 5 and Line 6. Summarizing and analyzing the basic parameters, physical and mechanical parameters of stratum, excavation process, and excavation depth of each layer of the 20 foundation pits, we standardized the subway foundation pits in this area. The statistical results are shown in Tables 1 and 2.

Based on the above statistical results and related design schemes, the main parameters of the standardized model are obtained, as shown in Table 3. The average value of each index in Table 1 is used to calculate the basic parameters of the foundation pit and underground continuous wall. In this study, the internal support uses the layout form with the highest proportion, which is one concrete support and three steel supports, and the specifications are based on the weak comprehensive stiffness.

3.3. The Rationality Verification of the Standardized Model. In this study, for finite element analysis, the HSS (rolling soil model with small strain stiffness) constitutive model $[16,17]$ 
TABle 1: The basic statistics of the excavation with an open cut.

\begin{tabular}{|c|c|c|c|c|c|c|}
\hline $\begin{array}{l}\text { Serial } \\
\text { number }\end{array}$ & Station & $\begin{array}{l}\text { Excavation } \\
\text { length } L(\mathrm{~m})\end{array}$ & $\begin{array}{c}\text { Excavation width } \\
\text { B }(\mathrm{m})\end{array}$ & $\begin{array}{c}\text { Excavation depth } \\
\mathrm{He}(\mathrm{m})\end{array}$ & $\begin{array}{c}\text { Depth of retaining } \\
\text { structure into soil H (m) }\end{array}$ & $\begin{array}{c}\text { The wall } \\
\text { thickness } t(\mathrm{~m})\end{array}$ \\
\hline 1 & Dan Bei road station & 199.9 & 19.5 & 16.2 & 33 & 0.8 \\
\hline 2 & $\begin{array}{c}\text { Vocational college } \\
\text { station }\end{array}$ & 241.6 & 20.5 & 16.4 & 29 & 0.8 \\
\hline 3 & $\begin{array}{c}\text { The Huaihe river road } \\
\text { station }\end{array}$ & 205.4 & 20.7 & 16.8 & 34.4 & 0.8 \\
\hline 4 & Chishing road station & 203.8 & 20.7 & 16.9 & 34.7 & 0.8 \\
\hline 5 & Siyuan road station & 191.08 & 20.7 & 17.0 & 31.9 & 0.8 \\
\hline 6 & $\begin{array}{c}\text { JianChang way } \\
\text { station }\end{array}$ & 294.2 & 20.7 & 16.7 & 34 & 0.8 \\
\hline 7 & Yueyahe road station & 183.8 & 20.7 & 16.7 & 41.5 & 0.8 \\
\hline 8 & LingBin road station & 153.6 & 37.6 & 16.9 & 31.1 & 0.8 \\
\hline 9 & Nanhezhuang station & 202.4 & 20.7 & 15.4 & 32.5 & 0.8 \\
\hline 10 & Dabizhuang station & 205.5 & 20.7 & 16.8 & 32 & 0.8 \\
\hline 11 & $\begin{array}{c}\text { Admiralty street } \\
\text { station }\end{array}$ & 499.9 & 20.7 & 16.6 & 34.1 & 0.8 \\
\hline 12 & Xuzhuangzi station & 228.5 & 20.7 & 16.5 & 32 & 0.8 \\
\hline 13 & $\begin{array}{l}\text { Affiliated middle } \\
\text { school station }\end{array}$ & 307.6 & 29.6 & 16.8 & 30.5 & 0.8 \\
\hline 14 & $\begin{array}{c}\text { North of bamboo } \\
\text { station }\end{array}$ & 167 & 23.1 & 24.0 & 42 & 1 \\
\hline 15 & Yibin road station & 207 & 20.7 & 15.9 & 31.6 & 0.8 \\
\hline 16 & $\begin{array}{c}\text { Anshan west road } \\
\text { station }\end{array}$ & 223.3 & 22.7 & 16.8 & 29.0 & 0.8 \\
\hline 17 & Day tow station & 284.3 & 20.7 & 16.6 & 31.5 & 0.8 \\
\hline 18 & $\begin{array}{c}\text { First central hospital } \\
\text { station }\end{array}$ & 180.6 & 40.6 & 16.8 & 29.6 & 0.8 \\
\hline 19 & $\begin{array}{c}\text { Yukon beam way } \\
\text { station }\end{array}$ & 235 & 20.7 & 16.9 & 30.5 & 0.8 \\
\hline 20 & $\begin{array}{c}\text { Cultural centre } \\
\text { station }\end{array}$ & 168 & 25.05 & 24.5 & 52.6 & 1 \\
\hline
\end{tabular}

TABLE 2: Main excavated conditions of the foundation pit.

\begin{tabular}{lcc}
\hline Working condition & The construction content & Excavation depth \\
\hline I & Initial geostress & - \\
II & Construction of retaining structure and partition wall & - \\
III & $1 \mathrm{~m}$ excavation, set up the first concrete support & $1 \mathrm{~m}$ \\
IV & The first layer of soil excavation, set up a second steel support & $4 \mathrm{~m}$ \\
V & The second layer of soil excavation, set up a third steel support & $4 \mathrm{~m}$ \\
VI & The third layer of soil excavation, set up the fourth steel support & $4 \mathrm{~m}$ \\
VII & The fourth layer of soil excavation, excavation to the end & $4 \mathrm{~m}$ \\
\hline
\end{tabular}

TABLE 3: Main parameters of the normalized model.

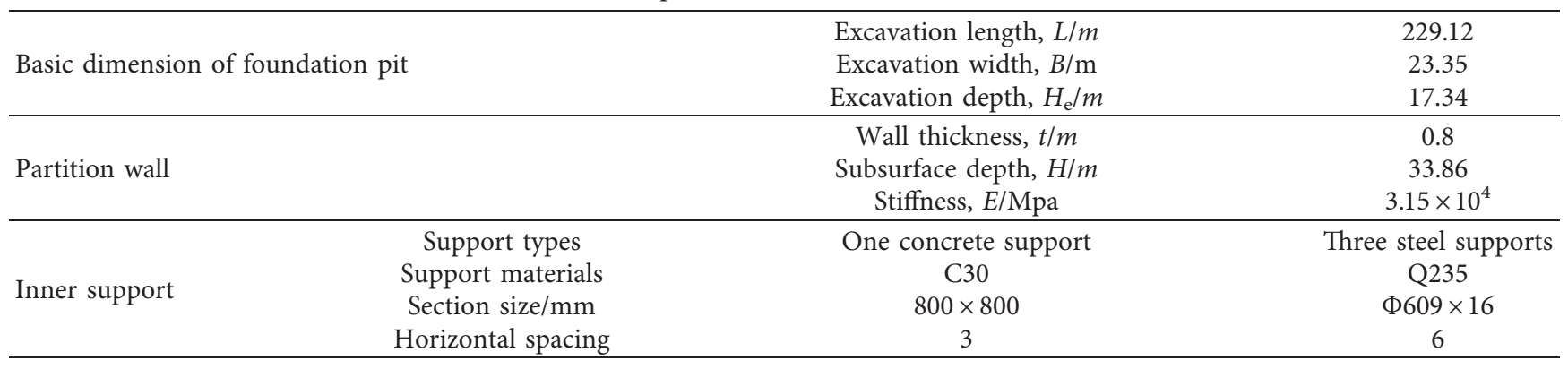

was used to take $1 / 2$ of the central axis of the above-standard foundation pit long side. To ensure the accuracy of the finite element analysis results, the calculation results were compared to relevant statistics in [13]. Physical and mechanical parameters of site soil layer are shown in Table 4, where $\gamma$ is the weight of the soil, $c^{\prime}$ is the effective cohesion of 
TABle 4: Physicomechanical parameters of the soils in the site.

\begin{tabular}{lccccccccccc}
\hline Strata & $\begin{array}{c}\text { Soil } \\
\text { thickness }(\mathrm{m})\end{array}$ & $\begin{array}{c}\gamma \\
\left(\mathrm{kN} / \mathrm{m}^{3}\right)\end{array}$ & $\begin{array}{c}c^{\prime} \\
(\mathrm{kPa})\end{array}$ & $\varphi^{\prime}\left(^{\circ}\right)$ & $\begin{array}{c}E_{s 0.1 \sim 0.2} \\
(\mathrm{MPa})\end{array}$ & $\begin{array}{c}E_{50}^{\text {ref }} \\
(\mathrm{MPa})\end{array}$ & $\begin{array}{c}E_{\text {oed }}^{\text {ref }} \\
(\mathrm{MPa})\end{array}$ & $\begin{array}{c}E_{u r}^{\text {ref }} \\
(\mathrm{MPa})\end{array}$ & $\begin{array}{c}G_{0}^{\text {ref }} \\
(\mathrm{MPa})\end{array}$ & $\begin{array}{c}\gamma_{0.7} \\
\left(10^{-3}\right)\end{array}$ & $\begin{array}{c}K \\
(\mathrm{~m} / \mathrm{d})\end{array}$ \\
\hline $\begin{array}{l}\text { Artificial fill } \\
\text { layer }\end{array}$ & 3.6 & 18.5 & 12.4 & 16.1 & 4.38 & 4.38 & 4.38 & 26.28 & 70.96 & 0.1 & 0.02 \\
Silty clay & 2.5 & 19.6 & 14 & 22.5 & 6.03 & 6.21 & 6.02 & 30.04 & 60.27 & 0.1 & 0.02 \\
Silty clay & 1.9 & 19.2 & 16 & 28.6 & 6.32 & 6.17 & 6.34 & 31.54 & 63.65 & 0.1 & 0.2 \\
Silt & 1.5 & 19.5 & 7.2 & 32.5 & 8.12 & 8.34 & 8.05 & 40.05 & 80.75 & 0.1 \\
Silty clay & 4.6 & 19.2 & 12.6 & 19.6 & 6.02 & 6.34 & 6.07 & 30.09 & 60.86 & 0.1 \\
Silty clay & 2.9 & 19.8 & 21.65 & 31.95 & 6.34 & 7.12 & 6.35 & 31.58 & 63.33 & 0.1 & 0.2 \\
Silt & 5 & 20.3 & 7.5 & 39.1 & 54.31 & 62.11 & 54.04 & 162.11 & 270.21 & 0.1 \\
Silty clay & 1.8 & 20.1 & 7.8 & 27.2 & 21.94 & 23.88 & 21.97 & 109.52 & 219.01 & 0.1 & 0.02 \\
Silt & 7.2 & 20.1 & 6.5 & 38.5 & 54.02 & 51.54 & 54.03 & 162.22 & 270.65 & 0.1 \\
Silty clay & 8.4 & 20.5 & 15.3 & 25.8 & 20.75 & 24.71 & 20.77 & 111.51 & 207.05 & 0.1 & 0.02 \\
\hline
\end{tabular}

the soil, $\varphi^{\prime}$ is the effective internal friction angle of the soil, $E_{S, 1 \sim 2}$ is the compression modulus of the soil, $E_{50}^{\mathrm{ref}}$ is the secant stiffness in standard drained triaxial test, $E_{\text {oef }}^{\text {ref }}$ is the tangent stiffness for primary oedometer loading, $E_{u r}^{\text {ref }}$ is the unloading/reloading stiffness at engineering stains, $G_{0}$ is reference shear modulus at very small strains, and $\gamma_{0.7}$ is the shear strain at which $G_{\mathrm{s}}=0.722 G_{0}$. Figure 2 and Table 5 show the specific calculation and comparison results, which agree with the measured values. As a result, further research can be conducted on this basis.

According to the measured and calculated results, the ground surface settlement mode after foundation pit excavation in Tianjin metro station is consistent with the settlement mode corrected by $\mathrm{Ou}$ et al. [18], as shown in Figure 3 . The relative distance between the maximum settlement point and the retaining structure is one-third the main influence range, where $d$ is the horizontal distance between any settlement point on the surface and the retaining structure in the same plane and $P I Z$ is the main area affected by surface settlement.

\section{Analysis of the Influence of Partition Wall Design Parameters on Deformation Control}

4.1. A Brief Introduction of the Orthogonal Finite Element Test. As illustrated in Figure 4, partition walls are constructed using the abovementioned standardized model, and an orthogonal test is performed to evaluate the impact of design parameters. Because the majority of the partition walls in existing practical projects are in the form of a continuous pile arrangement, this paper simplifies the partition wall composed of piles into the form of a continuous wall by reducing the size and stiffness; i.e., plate element is used for simulation.

First, the orthogonal test determined three primary partition wall design parameters: the horizontal distance between the partition wall and the same side retaining structure, the stiffness parameter, and the depth below ground. Second, during the orthogonal test, the partition wall was set within the range of settlement increase area (i.e., the horizontal distance between the maximum surface settlement point and the retaining structure) to observe the effect of the partition wall on the maximum surface settlement and the internal force of the retaining structure at the same time, as shown in Figure 5.

To establish the connection between partition wall design parameters and retaining structure, this study will use the ratio form of analysis parameters for testing, as shown in Table 6 , where $L_{0}, E_{0}$, and $H_{0}$ are the horizontal distances between the maximum surface settlement and the same side retaining structure, the stiffness parameters of the retaining structure, and the depth of the soil, respectively. There are three factors involved in the test, each with four levels. Under the condition that the number of tests is minimized, it is appropriate to use Table $\mathrm{L}_{16}\left(4^{5}\right)$ to arrange the test plan with a total of 16 tests. Each test plan and calculation result are shown in Table 7, among which the test results are the deformation of the foundation pit after the last step of excavation.

4.2. Comprehensive Analysis of Test Results. The test results show that the three factors have varying degrees of influence on the deformation control of the foundation pit (Table 8, Figure 6). Among them, $L / L_{0}$ has the most obvious influence on the partition wall, retaining structure and surface settlement, and is used as the main factor to study the mechanism of partition wall deformation control in this study. $H / H_{0}$ mainly affects the maximum lateral movement of the retaining structure. However, the change of $E / E_{0}$ has a relatively weak influence on foundation pit deformation. After comprehensive consideration, the rigidity of the partition wall was set as a medium in the follow-up study, i.e., $E / E_{0}=0.4$.

Based on the influence of the above factors on deformation control, this study obtained the influence law of $L / L_{0}$ and $\mathrm{H} / \mathrm{H}_{0}$ by increasing the value density of each factor and further analyzed the control mechanism of the partition wall on this basis.

\section{Mechanism Analysis of Partition Wall Design Parameters on Deformation Control}

5.1. The Influence of $L / L_{0}$ on Surface Subsidence $\delta v$. The influence of $L / L_{0}$ on surface settlement is mainly reflected in two aspects. The first is the change of settlement groove form. When $\mathrm{L} / L_{0} \leq 0.6$, the settlement form is a traditional groove 


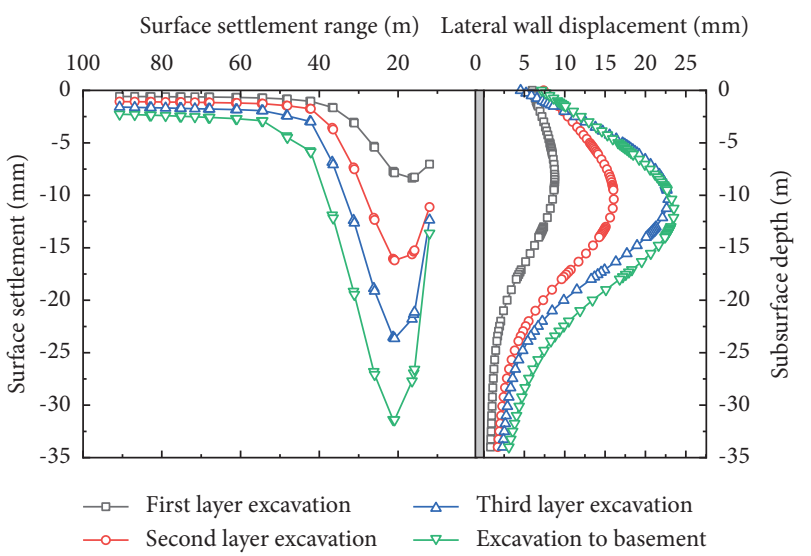

FIGURE 2: Surface settlement and lateral wall displacement of each excavated condition of the subway station foundation pit.

TABLE 5: Deformation comparison between analytical and measured values.

\begin{tabular}{|c|c|c|c|c|}
\hline \multirow[t]{2}{*}{ Working condition } & \multicolumn{2}{|c|}{ Maximum surface settlement } & \multicolumn{2}{|c|}{$\begin{array}{l}\text { Maximum lateral displacement of the } \\
\text { retaining structure }\end{array}$} \\
\hline & Measured mean value & Calculated value & Measured mean value & Calculated value \\
\hline First layer excavation and layer internal support & 12.77 & 11.06 & 7.77 & 8.77 \\
\hline Second layer excavation and layer internal support & 18.38 & 17.20 & 15.35 & 16.08 \\
\hline Third layer excavation and layer internal support & 22.71 & 23.65 & 20.41 & 22.80 \\
\hline Excavation to basement & 26.66 & 31.01 & 20.34 & 23.51 \\
\hline
\end{tabular}

shape, and the soil settlement between the partition wall and enclosure structure is very small (Figure $7(\mathrm{a})$ ). When L/ $L_{0}>0.6$, the partition wall divides the form of the settlement trough into double grooves, resulting in two troughs (there are two troughs for "maximum surface settlement" in the test results in Table 7 : No. 4, 8, 12, and 16), and the maximum settlement is located between the retaining structure and the partition wall, as shown in Figure 7(b).

The second is the influence on the maximum surface settlement $\delta_{\mathrm{vm}}$. When $\mathrm{L} / L_{0} \leq 0.6, \delta_{\mathrm{vm}}$ is controlled within the range of $7 \sim 11 \mathrm{~mm}$. Compared with the other side without a partition wall, the surface settlement decreases by $>60 \%$ and the control effect is obvious. When $L / L_{0}>0.6$, the value of $\delta_{\mathrm{vm}}$, which is outside the partition wall, changes in the range of $5 \mathrm{~mm} \sim 7 \mathrm{~mm}$, with little difference from that when $L / L_{0} \leq 0.6$, while the value of $\delta_{\mathrm{vm}}$ between the partition wall and the retaining structure changes in the range of $15 \sim 25 \mathrm{~mm}$.

Simultaneously, when compared to the other two test results, the maximum value of internal force and lateral displacement of the retaining structure also appears at an inflection point near $L / L_{0}=0.6$, and the maximum value of internal force and lateral displacement presents an upward trend. Resultantly, when $L / L_{0}>0.6$, the ability of the partition wall to control deformation gradually weakens as $L / L_{0}$ increases.

For this phenomenon, from a mechanical point of view, when $L / L_{0}<0.6$, the partition wall is located in $d / P I Z<0.2$, within the scope of the partition wall, and the retaining structure to provide the friction resistance of $f$ is larger than the soil subsidence that occurs between the two because of the gravity on the walls of $f^{\prime}$ negative skin friction resistance, as shown in Figure 8. When $L / L_{0}=0.6(d / P I Z>0.2), f$ is the largest, i.e., $f_{\max }=f^{\prime}$. When $L / L_{0}>0.6$, the dead weight of soil and $f^{\prime}$ between the two walls gradually increase. Moreover, while $f<f^{\prime}$, the partition wall's control effect on the deformation is relatively weakened.

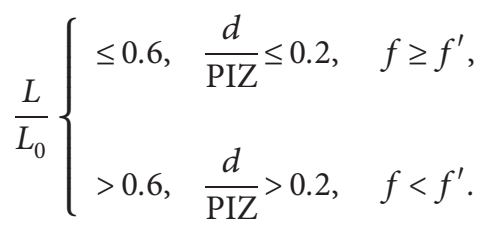

5.2. Influence of $L / L_{0}$ on Maximum Internal Force $M D$ of Retaining Structure. Due to the influence trend of $L / L_{0}$ on the change of maximum internal force of partition wall and retaining structure, this study introduces the calculation theory of Earth pressure distribution model of the "similar structure" double-row pile (Figure 9(a)) and analyzes the mechanism of $L / L_{0}$ 's influence on control effect from the mechanical perspective. Based on the theory, the ratio of active Earth pressure between the partition wall and retaining structure is calculated in the range of $L / L_{0}$, which is beneficial to control the deformation.

$$
\Delta_{P}=\frac{p_{a G}}{p_{a D}}
$$

where $p_{\mathrm{aG}}$ and $p_{\mathrm{aD}}$ are the active Earth pressure acting on partition wall and retaining structure, respectively.

As illustrated in Figure 9(b), it is assumed that there is active Earth pressure $\sigma_{a}$ acting on both the partition wall and retaining structure per unit length. Ignoring the interaction between the soil and structure, the soil between the two walls 


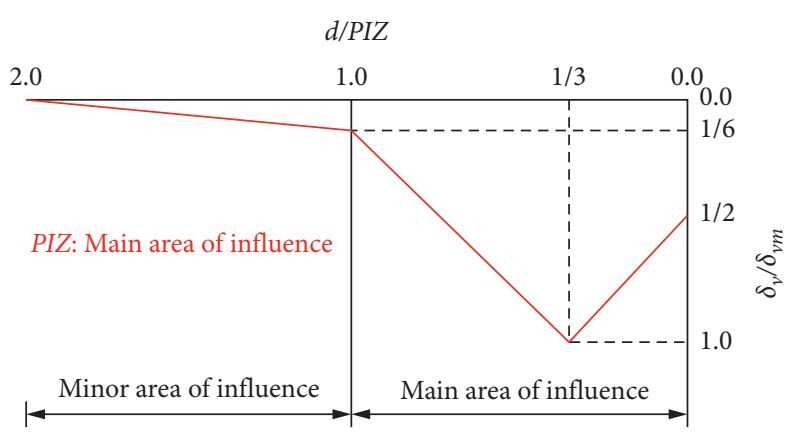

Figure 3: Surface settlement model.

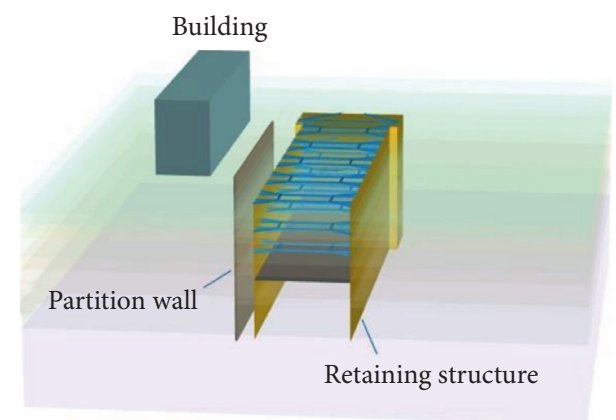

FIGURE 4: Schematic of the normalized model excavation.

will produce equal Earth pressure $\Delta \sigma_{a}$ on the front and rear walls, resulting in equal stress on both.

$$
\begin{gathered}
p_{a G}=\sigma_{a}-\Delta \sigma_{a}, \\
p_{a D}=\sigma_{a}+\Delta \sigma_{a} .
\end{gathered}
$$

Assuming that the ratio of $\Delta \sigma_{a}$ to $\sigma_{a}$ is the same at different depths,

$$
\Delta \sigma_{a}=\alpha \sigma_{a}
$$

where $\alpha$ is the Earth pressure distribution coefficient, which can be obtained by substituting it into (3) and (4) as follows:

$$
\begin{gathered}
p_{a G}=(1-\alpha) \sigma_{a}, \\
p_{a D}=(1+\alpha) \sigma_{a} .
\end{gathered}
$$

Accordingly, (2) can be expressed as

$$
\begin{aligned}
\Delta_{P} & =\frac{p_{a G}}{p_{a D}} \\
& =\frac{1-\alpha}{1+\alpha} .
\end{aligned}
$$

The Earth pressure distribution coefficient is calculated by dividing the weight of the sliding soil by the proportion of sliding between the partition wall and the retaining structure, i.e.,

$$
\alpha=\frac{2 L}{L_{0}^{\prime}}-\left(\frac{L}{L^{\prime}}\right)^{2}
$$

where $L_{0}^{\prime}=H_{e} \tan \left(45^{\circ}-\varphi / 2\right)$ is the horizontal distance between the intersection of the active slip surface and the pit surface and the retaining structure. After substituting (8) into (7), the following is obtained:

$$
\Delta_{P}=\frac{\left(\left(L / L_{0}^{\prime}\right)-1\right)^{2}}{2-\left(\left(L / L_{0}^{\prime}\right)-1\right)^{2}} .
$$

Since the traditional calculation method $L_{0}^{\prime}$ is determined according to the Rankine Earth pressure theory, and the existence of the retaining structure in practice will affect the distribution of the slip surface in the ideal state, the method of improving the starting position of the slip surface in [19] is used to determine the calculation of $L_{0}^{\prime}$.

We assume that the vertical distance between the improved sliding crack surface A and the excavation surface of the foundation pit is $t$ (Figure 10). In other words, at point A, the active Earth pressure is equal to the passive Earth pressure.

$$
\sigma_{A a}=\sigma_{A p}
$$

i.e.,

$$
k_{a} \gamma(H+t)=k_{p} \gamma t+2 c \sqrt{k_{p}},
$$

where $\gamma$ is the weight of soil, $c$ is the cohesion of soil, $H$ is the excavation depth of foundation pit, and $k_{a}$ and $k_{p}$ are the active and passive Earth pressure coefficients of soil, respectively. Accordingly,

$$
t=\frac{k_{a} \gamma H-2 c \sqrt{k_{p}}}{\left(k_{p}-k_{a}\right) \gamma} .
$$

According to the above improvements, the standardized model parameters are used for trial calculation. Accordingly,

$$
L_{0}^{\prime}=\left(H_{e}+t\right) \tan \left(45^{\circ}-\frac{\varphi}{2}\right)=10.2 m
$$

where $\varphi$ takes the mean value $\bar{\varphi}^{\prime}$ of the effective internal friction angle of silty clay typically distributed in the soft-soil area, and the horizontal distance $L_{0}$ between $L_{0}^{\prime}$ and maximum surface settlement and retaining structure is the same. Therefore, $L_{0}$ replaces $L_{0}^{\prime}$ in the following.

To compare the relationship between $\Delta_{P}$ and the internal force distribution between the partition wall and retaining structure, the internal force distribution ratio of the two is defined as

$$
\Delta_{M}=\frac{M_{G}}{M_{D}},
$$

where $M_{\mathrm{G}}$ and $M_{\mathrm{D}}$ are the maximum bending moments of the partition wall and retaining structure, respectively, which are calculated using the finite element method. Simultaneously, the orthogonal test $L / L_{0}$ values were substituted in (9) for calculation. To make the investigation and establishment of the relationship between $\Delta_{P}$ and $\Delta_{M}$, this study uses semilogarithmic coordinates to fit 


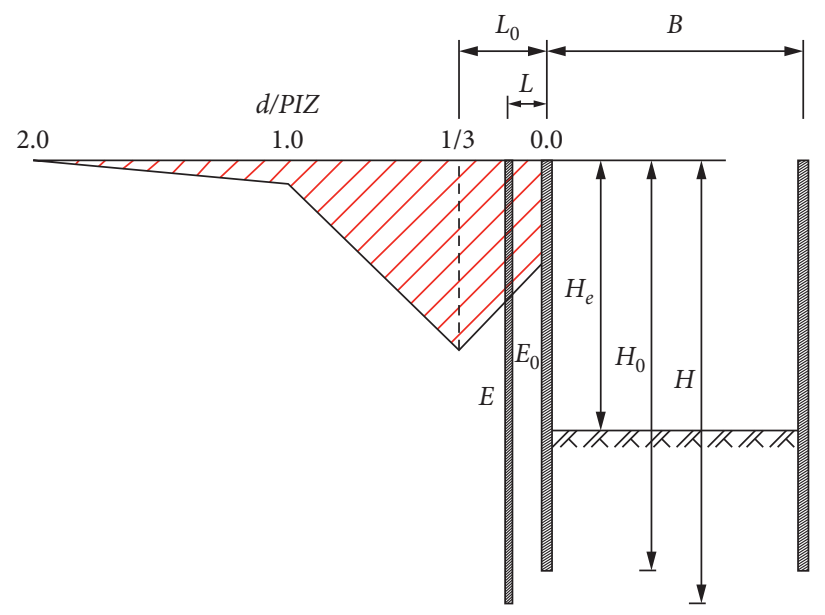

FIGURE 5: Schematic of the relationship between partition wall and foundation pit.

TABLE 6: Main factors and levels of the orthogonal test.

\begin{tabular}{|c|c|c|c|c|c|}
\hline \multicolumn{2}{|c|}{ Factors } & \multicolumn{4}{|c|}{ Test conditions } \\
\hline & & \multirow{2}{*}{$\begin{array}{c}\text { Condition } 1 \\
0.2\end{array}$} & \multirow{2}{*}{$\begin{array}{c}\text { Condition } 2 \\
0.4\end{array}$} & \multirow{2}{*}{$\frac{\text { Condition } 3}{0.6}$} & \multirow{2}{*}{$\begin{array}{c}\text { Condition } 4 \\
0.8\end{array}$} \\
\hline A & $L / L_{0}$ & & & & \\
\hline B & $E / E_{0}$ & 0.2 & 0.4 & 0.6 & 0.8 \\
\hline $\mathrm{C}$ & $\mathrm{H} / \mathrm{H}_{0}$ & 1 & 1.2 & 1.4 & 1.6 \\
\hline
\end{tabular}

TABle 7: Orthogonal test table.

\begin{tabular}{|c|c|c|c|c|c|c|c|c|}
\hline \multirow{2}{*}{$\begin{array}{l}\text { Test } \\
\text { number }\end{array}$} & \multirow[b]{2}{*}{$L / L_{0}$} & \multirow[b]{2}{*}{$E / E_{0}$} & \multirow[b]{2}{*}{$H / H_{0}$} & \multicolumn{2}{|c|}{ Partition wall } & \multicolumn{2}{|c|}{ Retaining structure } & \multirow{2}{*}{$\begin{array}{c}\text { The Earth's surface } \\
\text { The largest } \\
\text { settlement }(\mathrm{mm})\end{array}$} \\
\hline & & & & $\begin{array}{l}\text { Maximum bending } \\
\text { moment }(\mathrm{kN} \cdot \mathrm{m})\end{array}$ & $\begin{array}{c}\text { Maximum } \\
\text { lateral }(\mathrm{mm})\end{array}$ & $\begin{array}{l}\text { Maximum bending } \\
\text { moment }\left(10^{3} \mathrm{kN} \cdot \mathrm{m}\right)\end{array}$ & $\begin{array}{c}\text { Maximum } \\
\text { lateral }(\mathrm{mm})\end{array}$ & \\
\hline 1 & 0.2 & 0.2 & 1.6 & 260.12 & 14.31 & 1.21 & 12.82 & 9.91 \\
\hline 2 & 0.4 & 0.2 & 1 & 219.43 & 15.71 & 1.21 & 15.71 & 12.15 \\
\hline 3 & 0.6 & 0.2 & 1.4 & 141 & 10.61 & 1.23 & 12.78 & 7.74 \\
\hline 4 & 0.8 & 0.2 & 1.2 & 83.26 & 8.3 & 1.34 & 14.38 & $15.59(6.28)$ \\
\hline 5 & 0.2 & 0.4 & 1.4 & 423.5 & 13.53 & 1.15 & 12.46 & 9.62 \\
\hline 6 & 0.4 & 0.4 & 1.2 & 335.15 & 12.94 & 1.14 & 12.69 & 9.78 \\
\hline 7 & 0.6 & 0.4 & 1.6 & 215.67 & 9.64 & 1.22 & 12.28 & 6.94 \\
\hline 8 & 0.8 & 0.4 & 1 & 133.05 & 8.69 & 1.34 & 14.98 & $16.34(6.83)$ \\
\hline 9 & 0.2 & 0.6 & 1 & 563.08 & 16.18 & 1.12 & 15.3 & 12.75 \\
\hline 10 & 0.4 & 0.6 & 1.6 & 424.08 & 11.26 & 1.11 & 11.35 & 8.25 \\
\hline 11 & 0.6 & 0.6 & 1.2 & 279.01 & 10.19 & 1.21 & 12.86 & 7.74 \\
\hline 12 & 0.8 & 0.6 & 1.4 & 157.4 & 7.39 & 1.34 & 13.93 & $15.3(5.47)$ \\
\hline 13 & 0.2 & 0.8 & 1.2 & 655.39 & 13.15 & 1.06 & 12.52 & 9.81 \\
\hline 14 & 0.4 & 0.8 & 1.4 & 499.5 & 11.12 & 1.09 & 11.39 & 8.29 \\
\hline 15 & 0.6 & 0.8 & 1 & 333.2 & 10.9 & 1.20 & 13.53 & 8.61 \\
\hline 16 & 0.8 & 0.8 & 1.6 & 181.34 & 6.99 & 1.34 & 13.74 & $15.18(5.07)$ \\
\hline
\end{tabular}

Table 8: Average of the different levels for each factor.

\begin{tabular}{|c|c|c|c|c|c|c|c|c|c|c|c|c|c|c|c|}
\hline \multirow{3}{*}{ Level } & \multicolumn{6}{|c|}{ Partition wall } & \multicolumn{6}{|c|}{ Retaining structure } & \multirow{2}{*}{\multicolumn{3}{|c|}{$\begin{array}{c}\text { The Earth's } \\
\text { surface } \\
\text { The largest } \\
\text { settlement }(\mathrm{mm})\end{array}$}} \\
\hline & \multicolumn{3}{|c|}{$\begin{array}{l}\text { Maximum bending } \\
\text { moment }(\mathrm{kN} \cdot \mathrm{m})\end{array}$} & \multicolumn{3}{|c|}{$\begin{array}{l}\text { Maximum lateral } \\
\qquad(\mathrm{mm})\end{array}$} & \multicolumn{3}{|c|}{$\begin{array}{l}\text { Maximum bending } \\
\text { moment }(\mathrm{kN} \cdot \mathrm{m})\end{array}$} & \multicolumn{3}{|c|}{$\begin{array}{l}\text { Maximum lateral } \\
\qquad(\mathrm{mm})\end{array}$} & & & \\
\hline & $\bar{A}$ & $\bar{B}$ & $\bar{C}$ & $\bar{A}$ & $\bar{B}$ & $\bar{C}$ & $\bar{A}$ & $\bar{B}$ & $\bar{C}$ & $\bar{A}$ & $\bar{B}$ & $\bar{C}$ & $\bar{A}$ & $\bar{B}$ & $\bar{C}$ \\
\hline 1 & 475.5 & 175.9 & 312.2 & 14.3 & 12.2 & 12.9 & 1140 & 1250 & 1220 & 13.3 & 13.9 & 14.9 & 10.5 & 9.0 & 10.1 \\
\hline 2 & 369.5 & 276.8 & 338.2 & 13.0 & 11.2 & 11.2 & 1140 & 1210 & 1190 & 12.8 & 13.1 & 13.1 & 9.6 & 8.3 & 8.4 \\
\hline 3 & 242.2 & 355.9 & 305.4 & 10.3 & 11.3 & 10.7 & 1220 & 1200 & 1200 & 12.9 & 13.3 & 12.6 & 7.8 & 8.6 & 7.8 \\
\hline 4 & 138.8 & 417.4 & 270.3 & 7.8 & 10.5 & 10.6 & 1340 & 1170 & 1220 & 14.3 & 12.8 & 12.6 & 5.9 & 7.9 & 7.5 \\
\hline$R$ & 336.8 & 241.4 & 67.9 & 6.5 & 1.9 & 2.3 & 200 & 80 & 30 & 1.5 & 1.1 & 2.3 & 4.6 & 1.1 & 2.6 \\
\hline Factor to sort & 1 & 2 & 3 & 1 & 3 & 2 & 1 & 2 & 3 & 2 & 3 & 1 & 1 & 3 & 2 \\
\hline
\end{tabular}



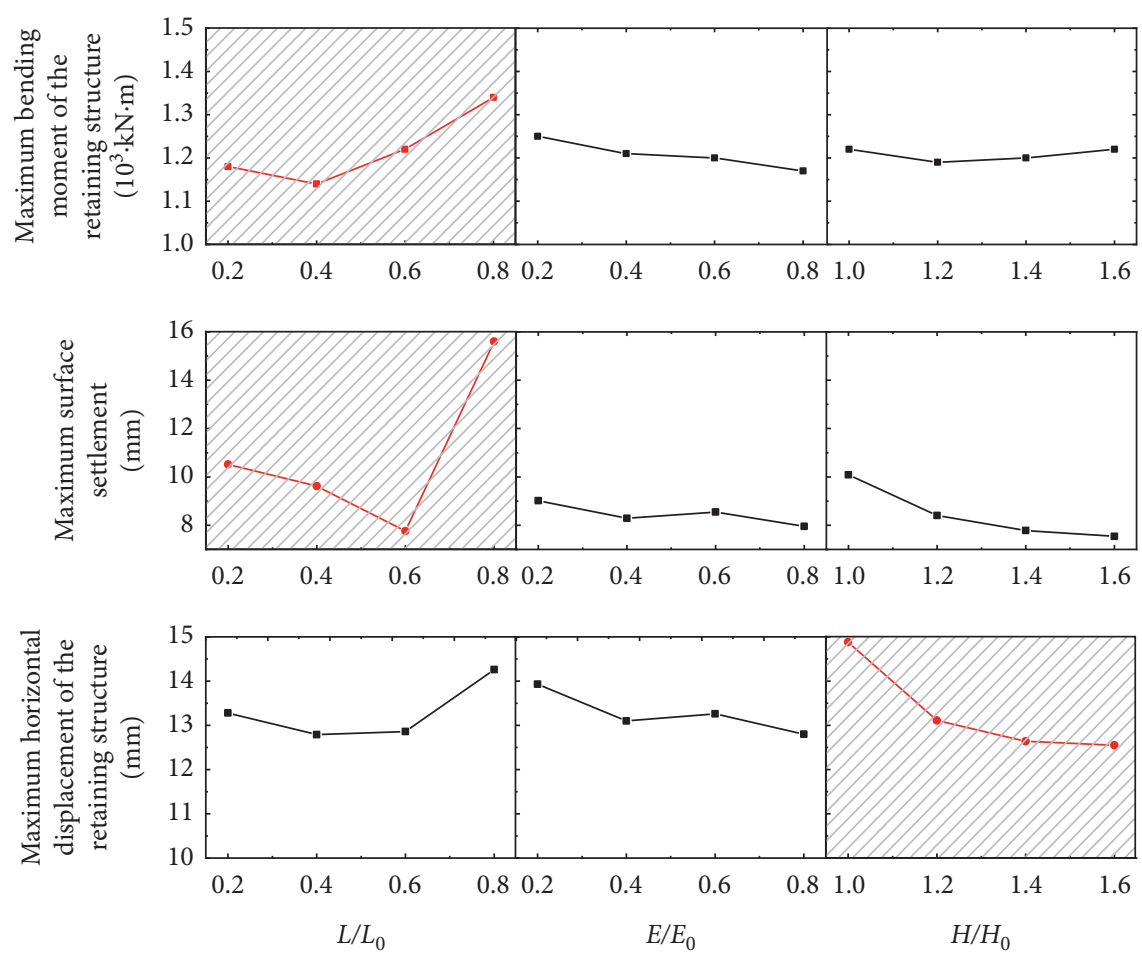

Figure 6: Trends of the affection at different levels.

Surface settlement range $(\mathrm{m})$

Surface settlement range $(\mathrm{m})$

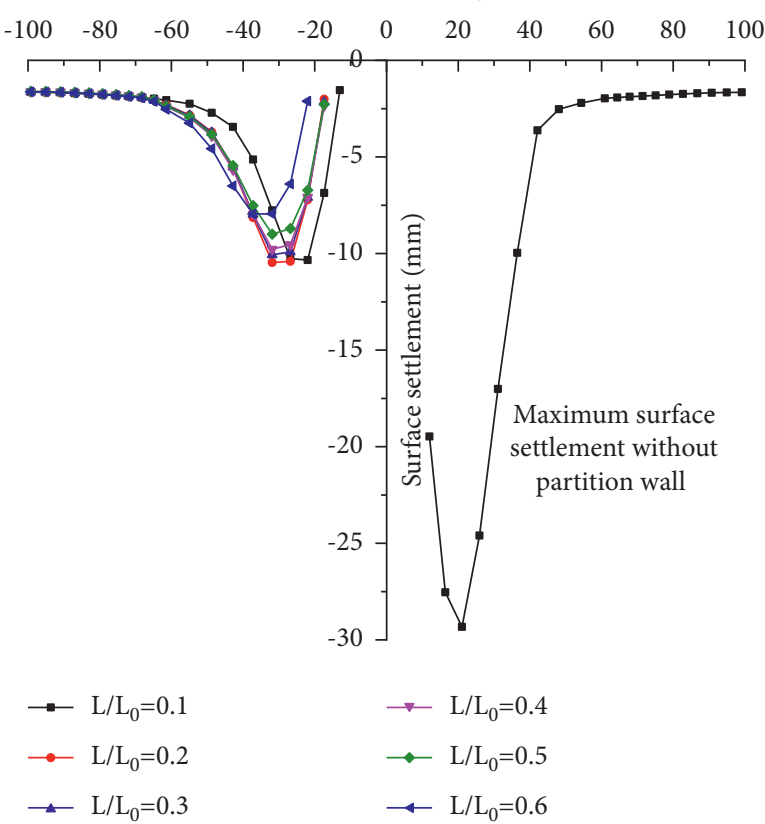

(a)

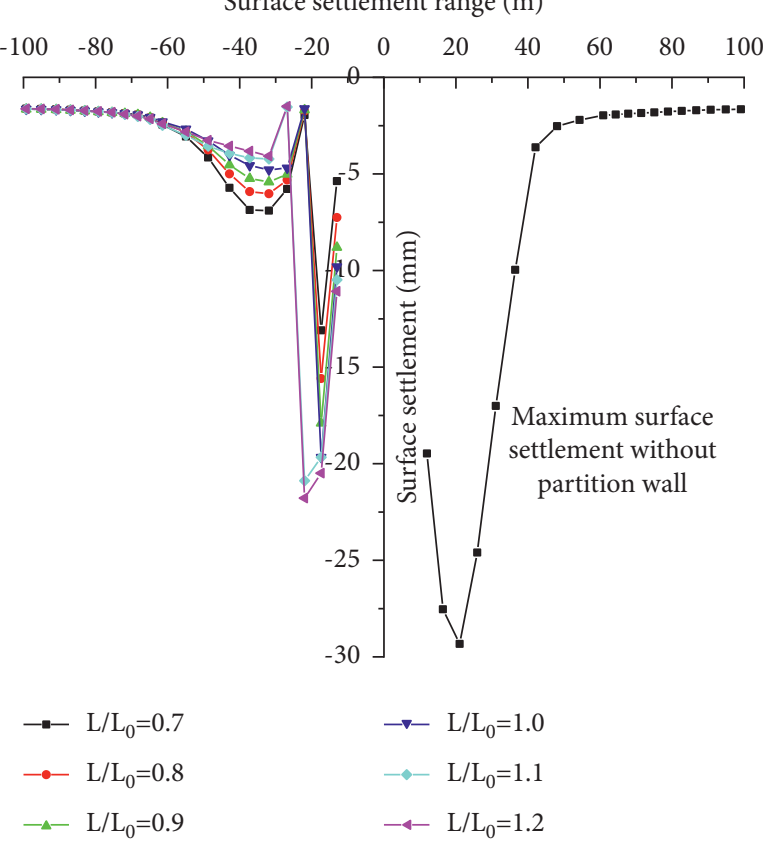

(b)

Figure 7: Affection of $L / L_{0}$ on the maximum ground settlement and the settlement form. (a) $L / L_{0} \leq 0.6$. (b) $L / L_{0}>0.6$.

$\Delta_{M}-\ln \left(L / L_{0}\right)$ curve and $\Delta_{P}-\ln \left(L / L_{0}\right)$ curve, respectively (Figure 11).

By comparing the relationship between $\Delta_{P}$ and $L / L_{0}$ and between $\Delta_{M}$ and $L / L_{0}$, it is observed that the changing trend of the two curves is the same, i.e., the partition wall's Earth pressure gradually decreases with the increase of $L / L_{0}$, which is consistent with the orthogonal test analysis result. Consequently, the Earth pressure distribution theory of doublerow piles can also be used to determine the internal force distribution between the partition wall and the retaining structure, and the relationship between the two can be expressed as 


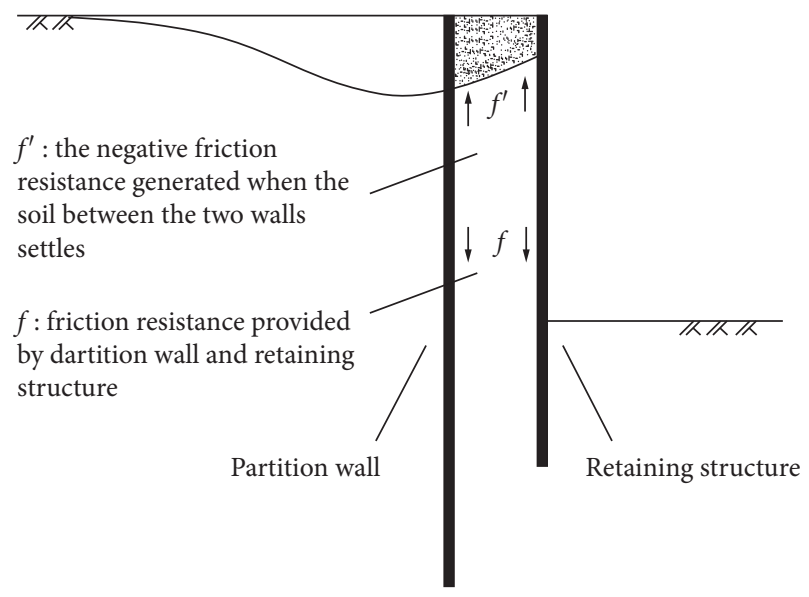

Figure 8: Schematic of the force diagram for ground settlement.

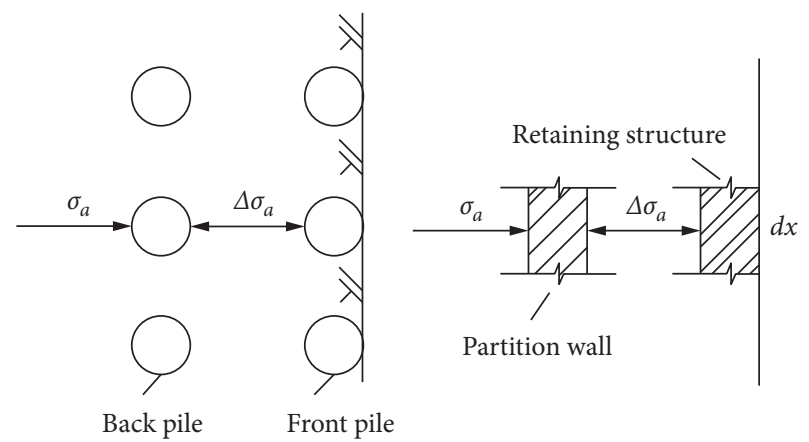

Figure 9: Schematic of the soil-stress comparison.

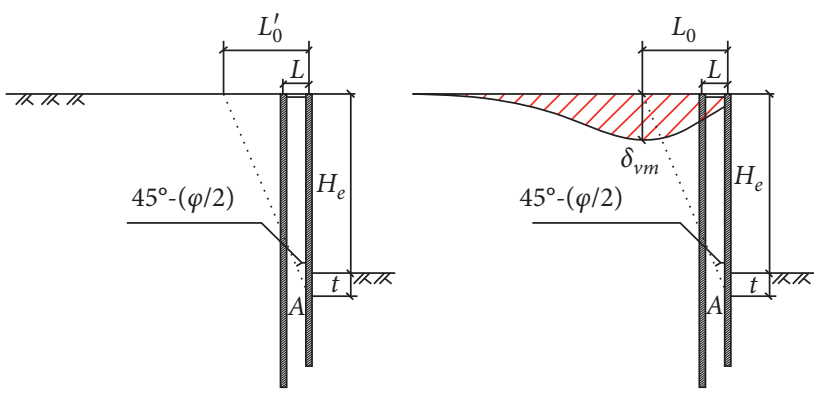

FIgURE 10: Schematic of the modified slip surface.

$$
\Delta_{M}=\Delta_{P}+0.05
$$

Therefore, according to the actual engineering situation, the partition wall is set within the range conducive to the control of the retaining structure's internal force. Following the determination of the maximum internal force of the retaining structure during the design stage, (15) can be used to quantitatively analyze the influence of $L / L_{0}$ on the partition wall to share the retaining structure internal force, internal force control, and retaining structure deformation.

5.3. The Influence of $\mathrm{H} / \mathrm{H}_{0}$ on the Maximum Lateral Movement $\mathrm{Shm}$ of the Retaining Structure. In addition to the partition wall's position ratio $L / L_{0}$, the ratio of the depth below the

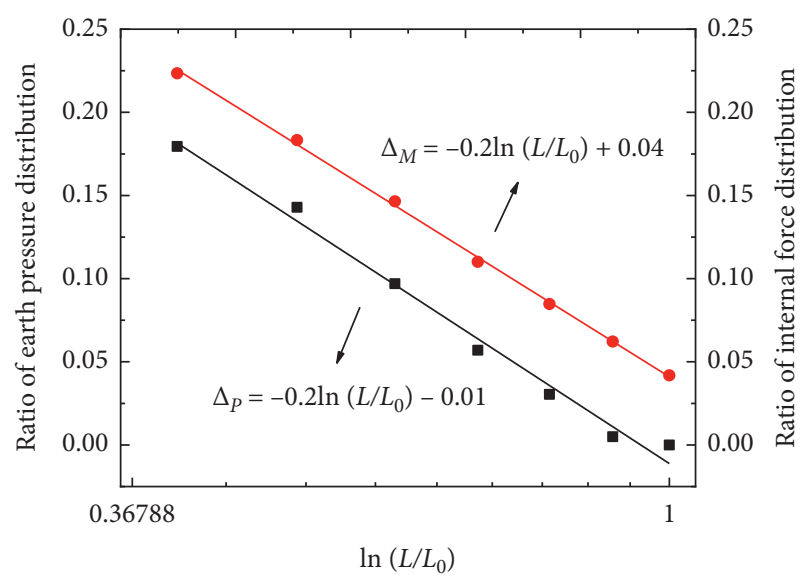

- Ratio of earth pressure distribution

- Ratio of internal force distribution

Figure 11: Relation curve of $\Delta_{M}-\ln \left(L / L_{0}\right)$ and $\Delta_{P}-\ln \left(L / L_{0}\right)$.

ground $\mathrm{H} / \mathrm{H}_{0}$ also has an obvious effect on controlling the retaining structure's maximum lateral movement. Based on the study of $L / L_{0}$, to analyze the specific influence of $H / H_{0}$ to $\delta_{\text {hm }}$, we set $L / L_{0}=0.6$ (which is the optimal position), the $H /$ $H_{0}$ value $0.5 \sim 2.0$ for finite element analysis, normalizing the analysis results of $\delta_{\mathrm{hm}}$, and exponential function is used to describe the relationship between maximum lateral movement control and $\mathrm{H} / \mathrm{H}_{0}$, as shown in Figure 12.

When $\delta_{h m}^{\text {con }}$ is the lateral movement of the retaining structure when $\mathrm{H} / \mathrm{H}_{0}$ changes in the range of $0.5 \sim 2.0$, and $\delta_{\mathrm{hm}}$ is the maximum lateral movement of the retaining structure when no partition wall is set $(H=0)$,

$$
\delta_{h m}^{\text {con }}=\delta_{h m}\left(3 e^{-\left(3.6 H / H_{0}\right)}+0.5\right) .
$$

It can be seen from the relationship curve between $\delta_{h m}^{\text {con }}$ and $H / H_{O}$ that, with the increase of partition wall penetration depth, the maximum lateral movement of the retaining structure can be reduced to $\sim 50 \%$ of that without a partition wall. When $H / H_{0} \leq 1.2$, the larger the value of $H$ is, the more obvious the control effect on the maximum lateral movement of the retaining structure is. However, when $\mathrm{H} /$ $H_{0}>1.2$, the maximum lateral shift almost does not continue to decrease.

In summary, before constructing a partition wall, the maximum lateral displacement of the retaining structure should be predicted using hydrogeological conditions of the actual engineering, the type of foundation pit, and the overall stiffness of the supporting structure. Secondly, in the risk assessment stage of engineering, according to the requirements of the foundation pit itself and the surrounding environment, the control target of the retaining structure deformation is set. Finally, based on the determining $L / L_{0}$, the penetration depth of the partition wall is calculated according to (16).

5.4. Applicability Verification of Action Mechanism. Based on the applicability of the constitutive model used in the finite element analysis, this study uses the prediction method of 


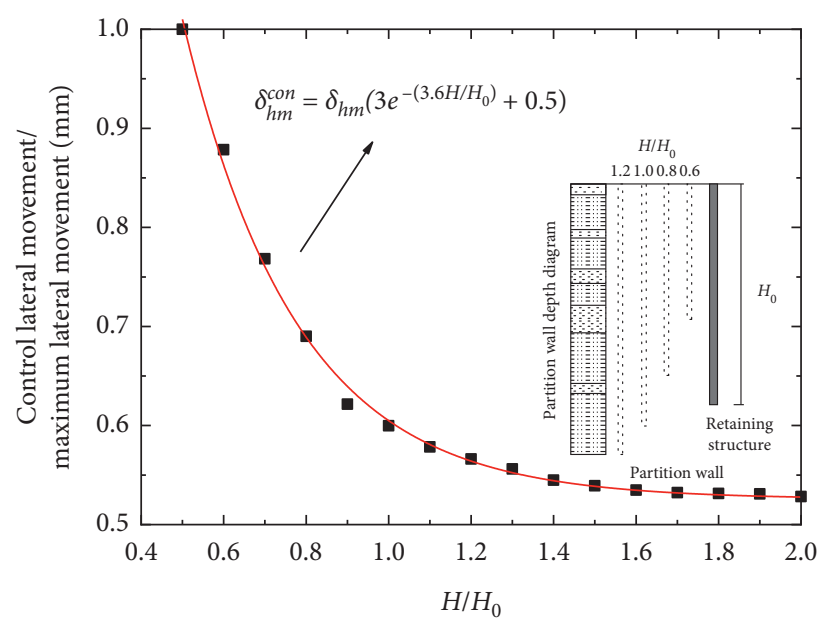

FIGURE 12: Relation curve between $\delta_{h m}^{\text {con }}$ and $\mathrm{H} / \mathrm{H} 0$.
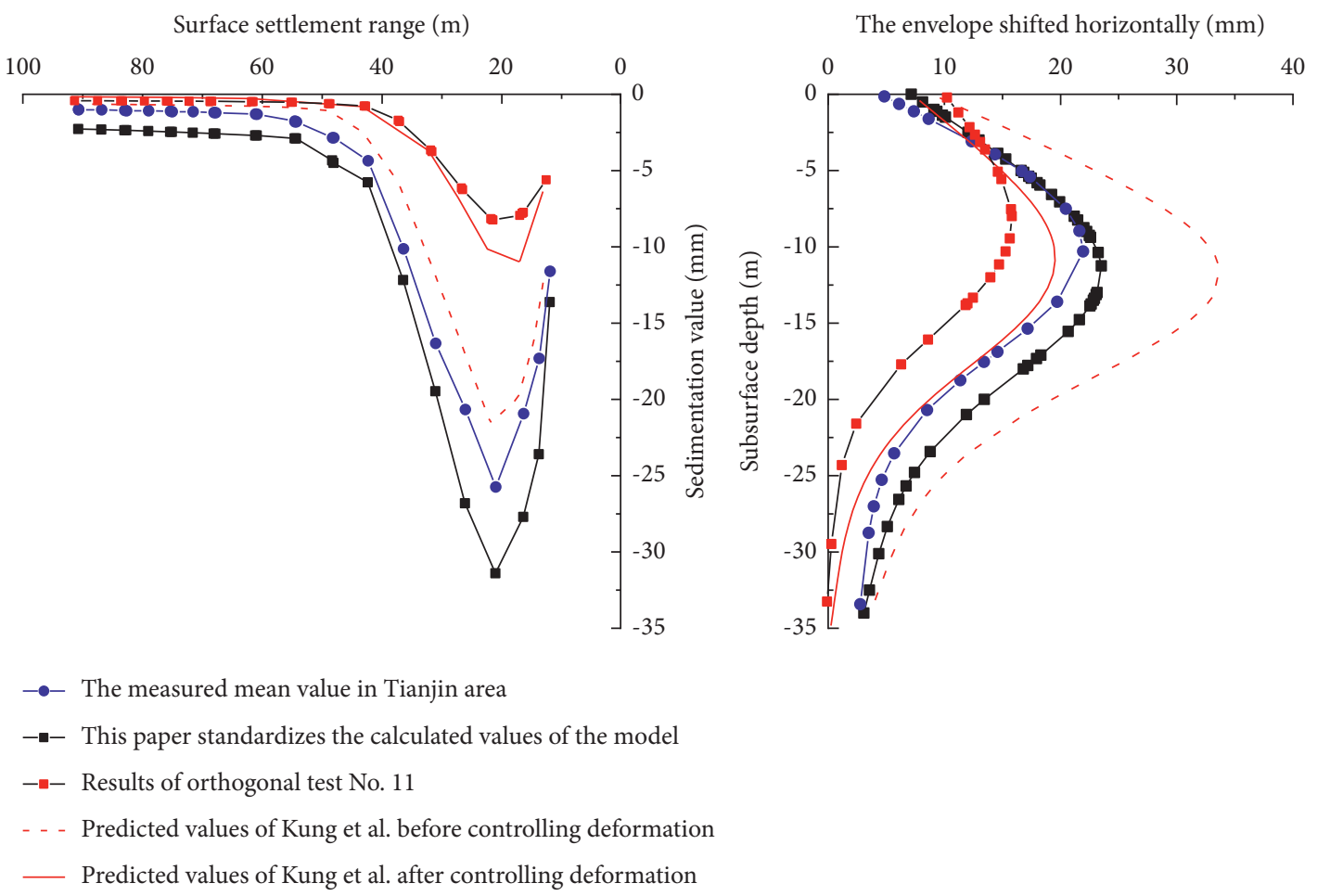

FIGURE 13: Result comparison among Kung et al.'s estimated and measured values and finite element calculation.

surface settlement outside the pit proposed by Kung et al. [20] using the reliability theory for soft soil and mediumhardness clay to verify the applicability of the partition wall controlling foundation pit deformation mentioned above in soft soil. The main steps for this are as follows.

Firstly, according to the main parameters of the standardized model of foundation pit in this paper, $\delta_{\mathrm{hm}}=34.74655 \mathrm{~mm}, R=0.66557$, and $\delta_{\mathrm{vm}}=23.12637 \mathrm{~mm}$ were calculated using the prediction method of Kung et al. before the control deformation. The predicted results were then compared to the average and maximum values of the measured surface settlement and lateral displacement of the retaining structure in the Tianjin foundation pit, as well as the calculated value of the finite element in this paper, and Figure 13 depicts the outcome of this comparison. Kung et al. calculated Tianjin's soft-soil area. The predicted value $\delta_{\mathrm{hm}}$ is larger and $\delta_{\mathrm{vm}}$ is lower than the measured average value. However, both are within the variation range of the measured value statistics [14] in this area $\left(20 \mathrm{~mm} \leq \delta_{\mathrm{hm}} \leq 40 \mathrm{~mm}, 10 \mathrm{~mm} \leq \delta_{\mathrm{vm}} \leq 30 \mathrm{~mm}\right)$.

Second, setting $L / L_{0}=0.6$ and $H / H_{0}=1.2$, we successively obtained the results determined by Kung et al. after 
setting the partition wall. The predicted values of the method were $\delta_{h m}^{\text {con }}=12.86 \mathrm{~mm}$ and $\delta_{v m}^{\text {con }}=7.74 \mathrm{~mm}$, and the predicted results were in good agreement with the calculated results of the No. 11 orthogonal test with the same parameter setting, as shown in Figure 13.

According to the results of the above analysis, the deformation prediction method proposed by Kung et al. can accurately predict the foundation pit deformation in Tianjin's soft-soil area. At the same time, the results of the analysis validate the study on the mechanism of the partition wall in soft-soil areas.

\section{Conclusion}

(1) The horizontal distance $L$ between the partition wall and enclosure structure mainly affects the internal force of enclosure structure and surface settlement outside pit. When $\mathrm{L} / L_{0}<0.6$, i.e., the partition wall is within the range of $d / P I Z<0.2$, the frictional resistance $f$ provided by the partition wall and the retaining structure is greater than the negative frictional resistance $f^{\prime}$ caused by the dead weight on the wall when the soil between the two is settled, and $f$ is the maximum when $L / L_{0}=0.6(d / P I Z>0.2)$, i.e., $f_{\max }=f^{\prime}$. At this point, the maximum surface settlement is inversely correlated with $L / L_{0}$. When $\mathrm{L} / L_{0}>0.6$, the dead weight of soil between the two walls increases gradually with $f^{\prime}$; i.e., $f$ is less than $f^{\prime}$, and the maximum surface settlement is positively correlated with $L / L_{0}$. In this case, the control effect of the partition wall on deformation is relatively weakened.

(2) The Earth pressure distribution theory of "similar structure" double-row pile is introduced to analyze its action mechanism, and the distribution relationship of Earth pressure and internal force between the partition wall and retaining structure is obtained, so that its influence can be quantified based on the influence trend of $L / L_{0}$ on the maximum internal force of partition wall and retaining structure.

(3) In addition to the partition wall position ratio $L / L_{0}$, the ratio of the depth below the ground surface $\mathrm{H} / \mathrm{H}_{\mathrm{O}}$ also has an obvious effect on controlling the maximum lateral movement of the retaining structure $\delta_{\mathrm{hm}}$. With the increase of partition wall penetration depth, the maximum lateral movement of the retaining structure can be reduced by $\sim 50 \%$ of that without a partition wall. When $H / H_{0} \leq 1.2$, the maximum lateral movement of the retaining structure can be controlled more clearly by increasing $H$. However, when $H / H_{0}>1.2$, the maximum lateral shift almost does not continue to decrease.

(4) Based on the abovementioned findings, the applicability of the partition wall mechanism controlling foundation pit deformation in soft soil was confirmed by implementing the prediction method of foundation pit deformation proposed by Kung et al.

\section{Abbreviation}

$L: \quad$ Length of the foundation pit's retaining structure

$B$ : Width of the foundation pit's retaining structure

$H_{e}$ : Excavation depth of the foundation pit's retaining structure

$H$ : Depth of the foundation pit's retaining structure

$t$ : Partition wall thickness

$E$ : $\quad$ Stiffness of the partition wall

$L_{0}$ : Horizontal distances between the maximum surface settlement and the same side retaining structure

$E_{0}$ : Stiffness parameters of the retaining structure

$H_{0}$ : Depth of the soil

$p_{\mathrm{aG}}$ : Active Earth pressure acting on partition wall

$p_{\mathrm{aD}}$ : Active Earth pressure acting on retaining structure

$L_{0}^{\prime}$ : Horizontal distance between the intersection of the active slip surface and the pit surface and the retaining structure

$M_{\mathrm{G}}$ : Maximum bending moments of the partition wall

$M_{\mathrm{D}}$ : Maximum bending moments of the retaining structure

$\delta_{\mathrm{hm}}: \quad$ Horizontal displacement of the containment structure

$\delta_{\mathrm{vm}}: \quad$ Surface subsidence

$\delta_{h m}^{\text {con }}$ : Lateral movement of the retaining structure

$\gamma: \quad$ Weight of the soil

$c^{\prime}$ : $\quad$ Effective cohesion of the soil

$\varphi^{\prime}$ : $\quad$ Effective internal friction angle of the soil

$E_{S, 1 \sim 2}$ : Compression modulus of the soil

$E_{50}^{\text {ref }}$ : Secant stiffness in standard drained triaxial test

$E_{o{ }^{r} d}^{\text {ref }}$ : Tangent stiffness for primary oedometer loading

$E_{u r}^{\text {ref }}$ : Unloading/reloading stiffness at engineering stains

$G_{0}$ : $\quad$ Reference shear modulus at very small strains

$\gamma_{0.7}$ : Shear strain at which $G_{\mathrm{s}}=0.722 G_{0}$.

\section{Data Availability}

The measured data used to support the findings of this study are included within the article.

\section{Conflicts of Interest}

The authors declare that they have no conflicts of interest.

\section{Acknowledgments}

This research was supported by the National Natural Science Foundation of China, Grant no. 51278233.

\section{References}

[1] G. Liu and W. Wang, Handbook for Foundation Pit Engineering, China Architecture And Building Press, Beijing, China, 2009.

[2] Y. Xiang, S. He, M. Zhang, Z. Cui, and S. Ma, "Constraint effect of pilot-drift and separation-pile structure on ground movements induced by shallow tunneling," Chinese Journal of Rock Mechanics and Engineering, vol. 23, no. 19, pp. 33173323, 2004. 
[3] H. Yao, M. Wang, D. Zhang, and C. Hao, "Mechanism of a driftpile system and analysis of its horizontal displacement," China Civil Engineering Journal, vol. 39, no. 4, pp. 105-109, 2006.

[4] W. Fei, "Application of isolation piles to deformation control of deep foundation pits close to buildings with shallow foundation," Chinese Journal of Geotechnical Engineering, vol. 32, no. S1, pp. 265-270, 2010.

[5] J. Zhai, J. Jia, and X. Xie, "Practice of partition wall in the building protection projects near deep excavation," Chinese Journal of Underground Space and Engineering, vol. 6, no. 1, pp. 162-166, 2010.

[6] H. Ying, T. Li, Y. Yang, and X. Xie, "Effect and application of partition walls in protecting adjacent buildings from deep foundation pits," Chinese Journal of Geotechnical Engineering, vol. 33, no. 7, pp. 1123-1129, 2011.

[7] H. Ying, T. Li, and W. Wang, "Optimization design of partition wall in deep excavations based on 3-D numerical simulation," Rock and Soil Mechanics, vol. 33, no. 1, pp. 220-226, 2012.

[8] E. Bilotta and G. Russo, "Use of a line of piles to prevent damages induced by tunnel excavation," Journal of Geotechnical and Geoenvironmental Engineering, vol. 137, no. 3, pp. 254-262, 2011.

[9] A. D. Mariano, J. M. Gesto, A. Gens, and H. Schwarz, "Ground deformation and mitigating measures associated with the excavation of a new metro line," Geotechnical Engineering in Urban Environments, pp. 1901-1906, Millpress Science, Rotterdam, Netherlands, 2007.

[10] J. Han, D. Liu, Y. Guan et al., "Study on shear behavior and damage constitutive model of tendon-grout interface," Construction and Building Materials, vol. 320, Article ID 126223, 2022.

[11] X. Ji, W. Zhao, S. Li, and Z. Zhou, "Application of isolation piles on metro tunnel for side-crossing the buildings with shallow foundation," Journal of Northeastern University, vol. 34, no. 1, pp. 135-139, 2013.

[12] J. Yan, The influence of pile foundation in life-cycle on adjacent existing tunnel, Ph.D Thesis, Shanghai Tong-ji University, Shanghai, China, 2007.

[13] G. Zheng, Y. Du, and Y. Diao, "Optimization analysis of efficiency of isolation piles in controlling the deformation of existing tunnels adjacent to deep excavation," Chinese Journal of Rock Mechanics and Engineering, vol. 34, no. S1, pp. 3499-3509, 2015.

[14] M. Ge, Study on Deformation Law and Influencing Factors of Foundation Fit Excavation in Soft Soil Area of Tianjin, Beijing Jiaotong University, Beijing, China, 2016.

[15] G. Zheng and Y. Jiao, Deep Foundation Pit Engineering Design Theory and Engineering Application, China Architecture and Building Press, Beijing, China, 2010.

[16] J. B. Burland, “"Small is beautiful”-the stiffness of soils at small strains," Ninth Laurits Bjerrum Memorial Lecture, Canadian Geotechnical Journal, vol. 26, no. 4, 1989.

[17] T. Benz, Small strain stiffness of soils and its numerical consequences, Institute of Geotechnical Engineering, University of Stuttgart, Stuttgart, Germany, [Ph.D], 2007.

[18] Z. Ou, Analysis and Design Theory and Practice of Deep Excavation Engineering, Science and technology books co. LTD, Taipei, Taiwan, 2002.
[19] G. T. Kung, C. H. Juang, E. C. Hsiao, and Y. M. Hashash, "Simplified model for wall deflection and ground-surface settlement caused by braced excavation in clays," Journal of Geotechnical and Geoenvironmental Engineering, vol. 133, no. 6, pp. 731-747, 2007.

[20] Kunming University of Science and Technology, Theoretical Analysis and Numericial Calculation of Retaining Structure with Double-Row Piles, Kunming University of Science and Technology, Kunming, China, 2013. 